started. The rate of health check ups was assessed in people aged 40 and over; the decreases in inpatient stay were assessed in the elderly. This raises the possibility that the rate of health check ups might be a marker for something else, perhaps the quality of health services, as Tatara et al suggest. Before suggesting that the relation that they found was causal, however, it would be necessary (at the very least) to have examined health check up rates in elderly people or to have followed up subjects for much longer.

Does this study have implications for European health services? If the relation is causal then the results are of potentially profound importance, suggesting that screening offered to middle aged people may reduce hospital costs incurred by elderly people. The results, however, are not relevant to the surveillance of patients aged 75 and over, which the new contract requires of general practitioners. They are obliged to check sensory functions (hearing and vision), mobility, mental condition, physical condition and continence, social environment, and use of medicines. The overlap between this and the Japanese programme is small. The paper by Tatara et al also raises the question of which components of their health checks are of value. Health professionals, obliged by governments to undertake check ups, reasonably expect that only those components with proved effectiveness will be included.

M G MARMOT

Professor of Community Medicine

A HAINES

Professor of Primary Health Care

University College and Middlesex School of Medicine,

University College London,

London WC1E 6EA

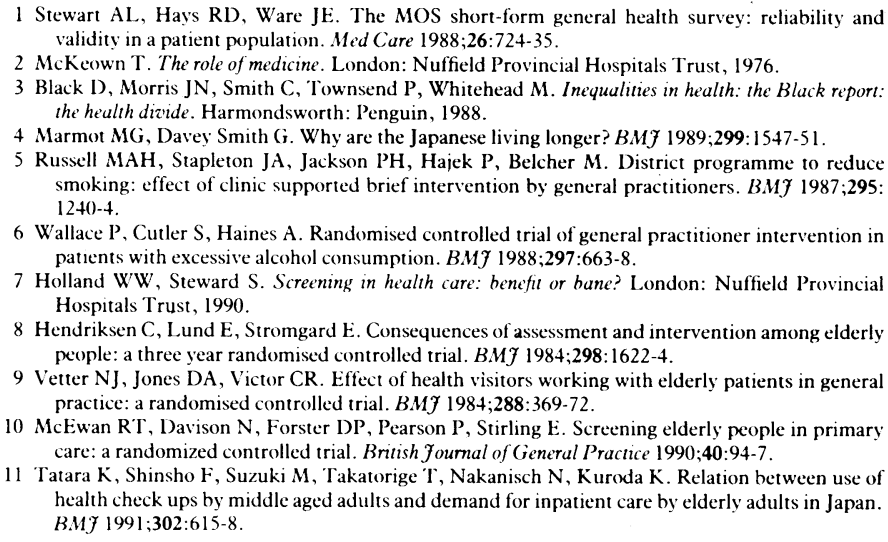

Stewart AL, Hays RD, Ware JE. The MOS short-form general health survey: reliability and validity in a patient population. Med Care 1988;26:724-35.

McKeown T. The role of medicine. London: Nuffield Provincial Hospitals Trust, 1976. 3 Black D, Morris JN, Smith C., Townsend P, Whitehead M. Inequalities in health: the Black report:

Marmot MG, Davey Smith G. Why are the Japanese living longer? BMf 1989;299:1547-51.

Russell MAH, Stapleton JA, Jackson PH, Hajek P, Belcher M. District programme to reduce smoking: effect of clinic supported brief intervention by general practitioners. BMF 1987;295: 1240-4.

6 Wallace P, Cutler S, Haines A. Randomised controlled trial of general practitioner intervention in patients with excessive alcohol consumption. BMF 1988;297:663-8.

Holland WW, Steward S. Screening in health care: benefit or bane? London: Nuffield Provincial Hospitals Trust, 1990

8 Hendriksen C, Lund E, Stromgard E. Consequences of assessment and intervention among elderly people: a three year randomised controlled trial. BMF 1984;298:1622-4.

9 Vetter NJ, Jones DA, Victor CR. Effect of health visitors working with elderly patients in general practice: a randomised controlled trial. $B M 7$ 1984;288:369-72.

10 Mre care: a randomized controlled trial. British foumal of General Practice 1990;40:94-7.

11 Tatara K, Shinsho F, Suzuki $M$, Takatorige T, Nakanisch N, Kuroda K. Relation between use of health check ups by middle aged adults and demand for inpatient care by elderly adults in Japan. BMF 1991;302:615-8.

\title{
What should be done about asymptomatic hypercholesterolaemia?
}

\section{A population based strategy of dietary change has been recommended for Canadians}

Screening hand luggage for explosive devices is widely accepted at airports throughout the world. In contrast, screening for hypercholesterolaemia, which in some people is analogous to carrying around a biological time bomb, is contentious. Several organisations have addressed this issue recently, ${ }^{1-5}$ but confusion still reigns on which policy to pursue. ${ }^{6}$ A report on blood cholesterol testing by the Standing Medical Advisory Committee currently being considered by the Department of Health should eventually dispel this confusion. ${ }^{7}$ In the mean time, an exhaustively thorough appraisal of the whole issue has just appeared from Canada. ${ }^{8}$

The $25-30 \%$ decrease in mortality from coronary heart disease observed in Canada between 1972 and 1982 occurred before screening had become widespread. As most of the coronary heart disease in a population occurs in the many with moderate hypercholesterolaemia rather than the few with severe hypercholesterolaemia, ${ }^{9}$ a population based strategy of dietary change would seem likely to be more effective than a. case finding approach. Although hypercholesterolaemia increases the relative risk of coronary heart disease, especially when accompanied by other risk factors, two thirds of men aged 55 between the highest quintiles of blood pressure and cholesterol remain free from coronary heart disease until the age of 70. Thus measurement of serum total cholesterol concentration is not a highly sensitive predictor of coronary heart disease, the report reasons, nor is prediction improved greatly by assaying high density lipoprotein cholesterol and triglyceride and calculating low density lipoprotein cholesterol concentration because the imprecision of these measurements often results in misclassification of risk.

The approach taken by the United States national cholesterol education programme, with its emphasis on the detection and treatment of people at risk, was rejected by the Toronto working group on the grounds of the massive expansion of laboratory and dietetic facilities that this would entail, the huge increase in time needed to manage hyperlipidaemia by doctors, and the costs of treating perhaps one in four adults with lipid lowering drugs.

Against this background the Toronto working group did not recommend mass screening but strongly advocated a population based strategy of dietary change, with opportunistic screening limited to those at high risk. These are mainly men aged 35-60 with other risk factors; those with known coronary heart disease were regarded separately. In agreement with most other advisory bodies, the Toronto working group accepted that a serum cholesterol concentration of less than $5.2 \mathrm{mmol} / \mathrm{l}$ is desirable whereas a value of more than $7 \cdot 8 \mathrm{mmol} / \mathrm{l}$ requires therapeutic intervention.

Not unexpectedly for epidemiologists, the Toronto working group focused its attention on the population rather than on people, whereas clinicians tend to take the opposite view. Thus in another recent review of screening, this time from the United States, three clinicians assessed the same evidence and reached similar conclusions but with one major difference: they advocated that all men have their serum cholesterol concentration measured at least once in early adult life, ${ }^{10}$ as does the British Hyperlipidaemia Association. ${ }^{1}$ This approach would ensure that those with a serum cholesterol concentration of more than $7.8 \mathrm{mmol} / \mathrm{l}$ due to genetic factors would be identified and treated as necessary. Changing the population's diet would be ineffective in such people, and they would often be missed if only those with other risk factors were screened. For example, a British survey suggests that screening everyone with a family history of coronary heart disease before 50 or who has a corneal arcus, a xanthelasma, or xanthomata would identify at most only $30 \%$ of individuals with a serum cholesterol concentration of more than $8 \mathrm{mmol} / \mathrm{l}$."

Would measuring the "newer" risk factors, such as apolipoprotein B and lipoprotein (a) improve the detection of people at high risk of coronary heart disease? A good case can be 
made for measuring apolipoprotein B concentration, which is sometimes raised in patients with coronary heart disease but with normal low density lipoprotein cholesterol concentrations, ${ }^{12}$ especially if they are hypertriglycerdaemic. Lack of prospective data and difficulties in standardising assays, however, have been used as counter arguments. ${ }^{13}$ In casecontrol studies lipoprotein (a) has proved to be a powerful discriminant between those with and without coronary heart disease,${ }^{14}$ but as with apolipoprotein $\mathrm{B}$ prospective data are scanty and there are problems with its assay. Once these limitations have been overcome, however, measurement of these and other emerging risk factors, including subspecies of high density lipoprotein, ${ }^{15}$ may help define more precisely the risk of coronary heart disease and thus enable decisions on whether to treat, for example, premenopausal women with hypercholesterolaemia, to be more soundly based.

GILBERT R/THOMPSON

Consultant Physician, MRC Lipoprotein Team,

Hammersmith Hospital, )

London)W $120 \mathrm{HS}$
I Shepherd J, Betteridge DJ, Durrington P, et al. Strategies for reducing coronary heart discase and desirable limits for blood lipid concentrations: guidelines of the British Hyperlipidaemi

2 British Cardiac Society Working Group on Coronary Prevention. Conclusions and recommendations. Br Heart f 1987;57:188-9.

3 Study Group, European Atherosclerosis Society. Strategies for the prevention of coronary hear disease: a policy statement of the European Atherosclerosis Society. Eur Hearl f 1987;8:77-88. 4 National Cholesterol Education Program. Report of the expert panel on detection, evaluation, and treatment of high blood cholesterol in adults. Arch Intern Med 1988;148:36-9.

5 National Cholesterol Education Program. Recommendations regarding public screening for measuring blood cholesterol. Summary of a National Heart, Lung, and Blood Institute workshop, October 1988. Arch Intern Med 1989;149:2650-4.

6 Leitch D. Who should have their cholesterol concentration measured? What experts in the United Kingdom suggest. BM7 1989;298:1615-6.

Smith R. Expert committee wants opportunistic cholesterol screening. BM7 1990;301:138-9.

8 Naylor CD, Basinski A, Frank JW. Rachlis MM. Asymptomatic hypercholesterolaemia: a clinical policy review. F Clin Epidemiol 1990;43:1029-1121.

Blicu W W of coronary heart disease. Ciruluion 1987;76 $\mathrm{su}$, Falk 1 ):164:7.

Garber AM, Sox HC, Littenberg B. Screening asymptomatic adults for cardiac risk factors: the Garber AM, Sox HC, Littenberg B. Screening asymptomati
serum cholesterol level. Ann Intern Med 1989;110:622-39.

11 Mann JI, Lewis B, Shepherd J, et al. Blood lipid concentrations and other cardiovascular risk factors: distribution, prevalence, and detection in Britain. BMF 1988;296:1702-6.

2 Sniderman AD, Silberberg J. Is it time to measure apolipoprotein B? Arteriosclerosis 1990;10:665-7 3 Vega GL, Grundy SM. Does measurement of apolipoprotein B have a place in cholesterol management? Arteriosclerosis 1990;10:668-71.

14 Seed M, Hoppichler F, Reavely D, et al. Relation of serum lipoprotein (a) concentration an apolipoprotein (a) phenotype to coronary heart disease in patients with familial hypercholesterolemia. $N$ Engl f Med 1990;322:1494-9.

15 Puchois P, Kandoussi A, Fievet P, et al. Apolipoprotein A-I containing lipoproteins in coronary artery disease. Atherosclerosis 1987;68:35-40.

\section{Unemployment: here we go again}

\section{Unemployment rising, evidence of harm strengthening}

Next week's official unemployment figures are likely to show unemployment again rising above two million in Britain. Using different definitions the Unemployment Unit calculates that it is already nearly three million, while the National Institute of Economic and Social Research uses the government definition to estimate that there will be another 500000 on the dole by next Christmas. The unemployment rate is even higher in Spain, Belgium, Canada, Australia, France, Italy, and some of the American states, and many countries may be in for a deep and prolonged recession. The rapid reappearance of mass unemployment (which has, of course, never gone away in Britain) has reawoken medical interest in the effects of unemployment, and while our attention was diverted by what J K Galbraith calls "an era of explosive securities speculation and financial manipulation" the evidence of harm has hardened.'

Galbraith, the world's most literate economist by far, gave evidence on unemployment to the Senate Committee on Labor and Human Resources in January and said: "Let us remind ourselves what lies behind those numbers - personal and family trauma, the loss of self esteem, the tight lipped fear about the future, the wonder as to whether there will be a job and income soon or ever again." He identified financial and real estate speculation and "the heavy transfer of spendable income from the poor to the rich" as causes of the recession. This year has also seen the publication of the most detailed study yet of the causes of unemployment over the past decade in Britain, and Professor David Worswick concludes that the best evidence refutes the classical economic wisdom that unemployment is caused by high real wages. ${ }^{2} \mathrm{He}$ also points out that the monetarist medium term financial strategy of the British government was a failure and carried a cost in terms of persistent and prolonged unemployment that was inordinately high. In other words, unemployment is not as inevitable as many governments would have us believe. This matters to doctors because all the radical solutions to the pain of unemployment lie with economists and politicians.

The evidence that unemployment kills-particularly the middle aged-now verges on the irrefutable. The classic spinoff from the longitudinal study of the Office of Population Censuses and Surveys showed that mortality was roughly a third higher in men seeking work at the time of the 1971 census compared with the whole group over the next decade. The study based on the 1981 data confirmed these results, which were further supported by similar studies from Italy and Denmark. ${ }^{6}$ Then last year saw the publication of a Finnish study that found mortality to be $90 \%$ higher among the unemployed than the employed after controlling for all background variables"; the study also showed a "doseresponse" relation, with mortality increasing with duration of unemployment. In all the studies death rates are particularly high from suicide, accidents and violence, and circulatory diseases. Further inroads into the mechanism of the increased mortality were produced by last year's Swedish study showing raised serum cholesterol concentrations and blood pressure in unemployed men, particularly those sleeping badly. ${ }^{8}$

The evidence of sleep disturbance ties in with the strong evidence of how unemployment harms mental health, which was admirably and completely summarised by Peter Warr, the leading researcher in the subject, in a monograph published in $1987 . .^{9} \mathrm{~A}$ recent study of 80 men normal at the time of redundancy found that $14 \%$ developed a "case" disorder of depression and anxiety and a further $17 \%$ developed a borderline case in the months after losing their jobs; pre-existing economic difficulty was one of the factors that made clinical depression more likely. ${ }^{10}$

During the time that unemployment has dropped in Britain the study of Beale and Nethercott of redundancy in a meat products factory in Wiltshire has come to further fruition, building on the original finding that men and women and their families threatened with redundancy increased consultation rates by $20 \%$ and outpatient hospital visits by $60 \%$ compared with controls." They have now shown that many of the increased consultations resulted from chronic conditions (requiring treatment for over one year), which were six times more common among the unemployed. ${ }^{12}$ Cardiovascular disorders were particularly common in the unemployed men. In a follow up study men who remained unemployed were 